FACULdADE DE CIÊNCIAS ECONÔ MICAS DA UFRGS

MACROECONOMIA DO BRASIL PÓS-1994 LUIZ CARLOS BRESSER-PEREIRA

DESENVOLVIMENTO ECONOMMICO, PREFERÊNCIA PELA LIQUIDEZ E ACESSO BANCÁRIO: UM ESTUDO DE CASO DAS MESORREGIÓES DE MINAS GERAIS

MARCO CROCCO, CLAUDIO BARRA DE CASTRO, ANDERSON CAVALCANTE E VANESSA DA COSTA VAL

FRIEDMAN E O MONETARISMO: A VELHA TEORIA QUANTITATIVA DA MOEDA E A MODERNA ESCOLA MONETARISTA

GENTIL CORAZZAE RODRIGO L. KREMER

BOLLHAS RACIONAIS, CICLO DE PREÇOS DE ATIVOS E RACIONALIDADE LIMITADA: UMA AVALIACAOO CRITICA DOS MODELOS NEOCLÁSSICOS DE BOLHAS ESPECULATIVAS JOSÉ LUIS OREIRO

VULNERABILITY INDICATORS OF THE TWIN CRISES: THE EAST ASIAN EPISODE

TITO BELCHIOR SILVA MOREIRA

IMPACTOS POTENCIAIS DA NEGOCIAÇÃO DA ALCA SOBRE OS INVESTIMENTOS EXTERNOS EM SERVIÇOS PROFISSIONAIS NO BRASIL

MICHEL ALEXANDRE, OTAVIANO CANUTO E GILBERTO TADEU LIMA

TEORIA MARXISTA DO VALOR: UMA INTRODUÇẢO ALFREDO SAAD FILHO

UM ESTUDO EMPIRICO DOS CICLOS POLITICO. ECONOOMICOS NO BRASIL

ATHOS PRATES DA SILVEIRA PREUSSLER E MARCELO SAVINO PORTUGAL

RELENDO CHANDLER, WILLIAMSON E NORTH PARA ENTENDER O PROCESSO DE FORMACĀO DAS ESTRADAS DE FERRO NO BRASIL

JEFFERSON ANDRONIO RAMUNDO STADUTO

WEIMAR FREIRE DA ROCHA IR. E CLAIITON ATAIDES DE FREITAS

MATRIZ DE INSUMO-PRODUTO PARA A ECONOMIA TURISTICA BRASILEIRA: CONSTRUCCÃO E ANÁLISE DAS RELAÇÓES INTERSETORIAIS

FRANCISCO CASIMIRO FILHO E JOAQUIM JOSÉ MARTINS GUILHOTO

SEÇĀO ESPECIAL: AVALIAÇŌES INICIAIS DA POLITTICA ECONÓMICA DO GOVERNO LULA

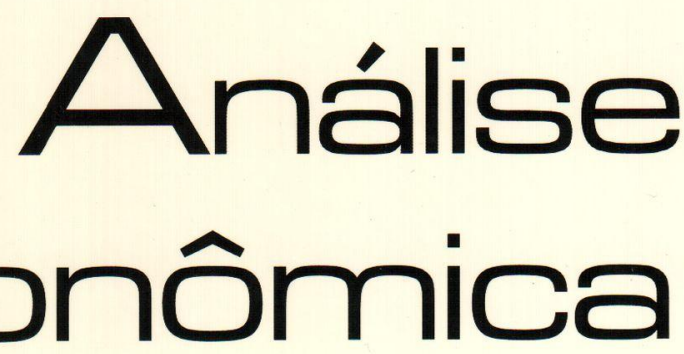


Universidade Federal do Rio Grande do Sul

Reitora: Profa. Wrana Maria Panizzi

Faculdade de Ciencias EConómicas

Diretora: Prof Pedro César Dutra Fonseca

Centro de Estudos e Pesquisas Economicas

Diretor: Prof. Gentil Corazza

Departamento de Ciéncias económicas

Chiefe: Prof. Ricardo Dathein

Curso de Pós. Graduação em Economia

Coordenador: Prof. Eduardo Pontual Ribeiro

Programa de Pós-Graduação em Desenvolvimento Rural

Coordenador: Prof. jalcione Almeida

CONSElHo EDITORIAL:

Carlos G. A. Mielitz Netto (UFRGS), Eduardo A. Maldonado Filho (UFRGS), Eduardo P. Ribeiro (UFRGS), Eleutério F. S. Prado (USP), Eugênio Lagemann (UFRGS), Fernando Cardim de Carvalho (UFRJ), Fernando Ferrari Filho (UFRGS), Fernando de Holanda Barbosa (FGV/RJ), Flávio Vasconcellos Comim (UFRGS), Gentil Corazza (UFRGS), Giácomo Balbinotto Netto (UFRGS), Gustavo Franco (PUC/RJ), Jan A. Kregel (UNCTAD), João Rogério Sanson (UFSC), Joaquim Pinto de Andrade (UnB), Jorge Paulo Araújo (UFRGS), Marcelo S. Portugal (UFRGS), Maria Alice Lahorgue (UFRGS), Paul Davidson (University of Tennessee), Paulo D. Waquil (UFRGS), Pedro C. D. Fonseca (UFRGS), Philip Arestis (Levy Economics Institut of Bard College), Roberto C. de Moraes (UFRGS), Ronald Otto Hillbrecht (UFRGS), Sabino da Silva Porto Jr. (UFRGS), Stefano Florissi (UFRGS) e Werner Baer (University of Illinois at UrbanaChampaign).

COMISSÃO EDITORIAL:

Eduardo Augusto Maldonado Filho, Fernando Ferrari Filho, Gentil Corazza, Marcelo Savino Portugal, Paulo Dabdab Waquil e Roberto Camps Moraes.

EDIroR: Prof. Fernando Ferrari Filho

Editor Adunnio: Prof. Gentil Corazza

SECRETÁrla: Clarissa Roncato Baldim

REVISÁO DE TEXTOS: Vanete Ricacheski

EDITORaÇão Eletrónica: Vanessa Hoffmann de Quadros

Fundador: Prof Antônio Carlos Santos Rosa

Os materiais publicados na revista Análise Econômica são da exclusiva responsabilidade dos autores. É permitida a reprodução total ou parcial dos trabalhos, desde que seja citada a fonte. Aceita-se permuta com revistas congêneres. Aceitam-se, também, livros para divulgação, elaboraçāo de resenhas e recensōes Toda correspondência, material para publicaçāo (vide normas na terceira capa), assinaturas e permutas devem ser dirigidos ao seguinte destinatário:

Análise Econômico

PROF FERNANDO FERRARI FILHO Revisła Análise Econômica - Av. João Pessoa, 52 CEP 90040-000 PORTO ALEGRE - RS, BRASL Telefones: (051) 316-3513 - Fax: (051) 316-3990 E-mail: rae@ufrgs.br

Ano 21, $n^{\circ} 39$, março, 2003 - Porto Alegre

Faculdade de Ciências Econômicas, UFRGS, 2003

Periodicidade semestral, março e setembro.

Tiragem: 500 exemplares

1. Teoria Econômica - Desenvolvimento Regional.

Economia Agrícola - Pesquisa Teórica e Aplicada -

Periódicos. I. Brasil

Faculdade de Ciências Econômicas,

Universidade Federal do Rio Grande do Sul 


\section{Os primeiros sete meses do Governo Lula e o debate com seus críticos}

Fernando J. Cardim de Carvalho*

\section{Da Herança Maldita à Conquista da Credibilidade}

Mesmo os mais ardorosos e otimistas seguidores de Lula e do PT admitiam, durante a campanha presidencial de 2002, que o primeiro ano de seu governo se daria em meio a importantes dificuldades e que sua política seria pautada em medida significativa pela, digamos, estratégia seguida por Fernando Henrique Cardoso. Lula teria de enfrentar limitações de natureza fiscal, por exemplo, já que seu primeiro ano de governo se daria no espaço delimitado pela lei orçamentária votada ainda em 2002. Outro limitante importante das opções do novo governo seria o acordo assinado com o FMI ainda em 2002, mas avalizado pelos candidatos à presidência, inclusive Lula.

No entanto, mesmo os mais ardorosos e leais seguidores de Lula devem estar se perguntando "o que houve?". O novo presidente parece ter abdicado de qualquer iniciativa na área macroeconômica, não apenas dando continuidade às políticas de Cardoso, como, na verdade, buscando sua radicalização e aprofundamento que surpreendem até mesmo seus adversários, que lhe criticam excessos, mas não a orientação de sua política.

O presidente, e a liderança política que lhe cerca, com a notável exceção do Ministro da Fazenda e da direção do Banco Central, refugiam-se na retórica da herança maldita. Este é o discurso que justifica todas as decisões tomadas nestes primeiros sete meses de 2003 pela necessidade de enfrentar a crise herdada de Fernando Henrique Cardoso. O rótulo é elástico, podendo ser aplicado a qualquer esfera que se deseje, mas, na maioria das vezes, a expressão herança maldita é usada em referência às pressões inflacionárias geradas pela desvalorização do real ocorrida em meados de $2002 \mathrm{e}$ à elevação das taxas de juros, pelo menos em parte causada pelos temores dos agentes financeiros de que Lula pudesse vir a

\footnotetext{
- Professor Titular, Instituto de Economia da UFRJ.
} 
reestruturar a dívida pública compulsoriamente. Por causa da herança maldita, o Governo Lula teria de comprometer seus primeiros meses com a conquista da credibilidade. Sua política econômica seria determinada pela necessidade de convencer os "mercados" de que o presidente era um político responsável, eliminando-se do cenário o risco de que as bravatas (como o presidente qualificou suas idéias passadas) que povoaram a retórica do PT desde a sua fundação pudessem ser efetivamente postas em prática no seu governo. As taxas de juros não apenas foram elevadas para além do que foi herdado de FHC, como a elevação foi decidida por uma diretoria do Banco Central que chegou ao limite do comportamento irracional para afirmar sua independência. Não satisfeito com esta demonstração de responsabilidade, o novo governo elevou as metas de superávit primário (destinado a garantir o serviço da dívida pública) para $4,25 \%$ do PIB, meio ponto acima do que o governo anterior havia acordado com o Fundo Monetário Internacional, perseguindo, na prática, superávits ainda maiores, mesmo que ao custo da virtual paralisação e inoperância da nova administração, já que estes superávits têm sido conseguidos através do corte de despesas do setor público, inclusive em gastos sociais.

O governo parecia alimentar a expectativa de que esta seria uma fase temporária, ou de transição, como a liderança do governo costuma dizer. Isto significava adiar a implantação do estilo PT de governo para uma época em que os mercados financeiros tivessem se acalmado e convencido das boas intençōes do presidente. $O$ que deveria acontecer então, é um tanto incerto. Alguns pareciam argumentar que quando o mercado "descesse a guarda", a mudança de modelo econômico poderia então ser buscada. Outros, porém, pareciam apostar que, uma vez conquistada a credibilidade junto aos "mercados", os investidores, domésticos e internacionais, voltariam a aplicar no país, reduzindo as taxas de juros, estimulando a economia e promovendo o crescimento econômico, permitindo a Lula promover os programas sociais que seriam a marca progressista do PT. Em outras palavras, para estes, que parecem hoje ser os mais representativos do pensamento do governo Lula, o estilo PT de governar seria a combinação de políticas econômicas conservadoras com políticas sociais mais amplas. A compatibilização entre estas duas características seria obtida pela retomada do crescimento, que deveria resultar do engajamento de investidores privados convencidos das boas intençōes do presidente. 
O governo Lula comemora o sucesso de seus primeiros meses pela redução da inflação (cujo perigo muitos consideram ter sido, conscientemente ou não, exagerados ao final de 2002) e pela boa acolhida de suas medidas pelo mercado financeiro, tão surpreso quanto os eleitores do presidente, pelo rumo tomado por ele. As decisões de elevação da taxa de juros por parte do Banco Central foram recebidas com o aplauso isolado desses mercados, que também se mostrou bastante compreensivo com a timidez, beirando a incompetência, com que o movimento de alta começou a ser revertido. O estado da economia real, por outro lado, é extremamente precário, por qualquer índice que se tome. Alem disso, os indicadores relevantes, como os planos de investimento, por exemplo, apontam para uma piora do quadro no futuro imediato.

\section{A Situação Macroeconômica}

A economia brasileira chega a julho entre sinais de que a estag. nação resultante da combinação de apertos monetário e fiscal pode se tornar uma recessão. Em certa medida, esta diferenciação é pouco importante. A economia brasileira vem crescendo abaixo de sua capacidade por duas décadas. A taxa de crescimento do PIB esperada para 2003, 1,5\%, segue esta tendência. Taxas de crescimento desta ordem são insuficientes para gerar os empregos necessários para absorver a população que se agrega ao mercado de trabalho, mesmo com o declínio observado nas taxas de crescimento demográfico há já algum tempo. O fenômeno do desemprego e do subemprego tornou-se uma constante, assombrando a sociedade brasileira com o fantasma da instabilidade política e social que traz consigo. Lula, que anunciou em sua campanha eleitoral a intenção de criar dez milhōes de empregos, já teve tempo de contribuir para aumento significativo da taxa de desocupação medida pelo IBGE. O aumento do desemprego e a redução da renda dos trabalhadores, causada também pela aceleração da inflação na virada de 2002 para 2003. levaram a uma queda do consumo privado, que agravou as pressões recessivas na economia.

A contração do consumo atingiu particularmente, mas não exclusivamente, os bens de consumo duráveis, desestimulando, como seria de se esperar, planos de investimento no setor e, indiretamente, planos de investimento dos fornecedores do setor. Na verdade, o único segmento em que expectativas de demanda poderiam se man- 
ter com alguma firmeza seria o setor exportador, que não depende da renda interna para realizar suas vendas. No entanto, algumas incertezas importantes cercam até mesmo esta atividade. De um lado, se não houver uma aceleração do crescimento da economia mundial, o sucesso em prosseguir expandindo exportaçő́es torna-se crucialmente dependente, por um lado, da adoção de uma política cambial mais ativa e, por outro, do aumento da produtividade nas empresas voltadas para o mercado externo, já que para se expandirem as exportações brasileira têm de tomar o lugar de outros competidores. A política cambial do governo Lula é, aparentemente, órfã. Quem teria a responsabilidade natural pela sua administração, o Banco Central, parece apegar-se a um fundamentalismo inacreditavelmente tolo e simplista, sob a alegação de que sua função é apenas perseguir metas inflacionárias e que a taxa de câmbio deve ser deixada livre para encontrar seu "ponto de equilibrio". Este mantra acabou repetido pelo próprio presidente da República, em entrevistas com a imprensa. Exportadores se defrontam não apenas com incertezas com relação ao que seria seu nível de equilíbrio, como também se vêem obrigados a conviver com a volatilidade do preço da moeda americana, alimentada pelos movimentos erráticos da conta de capitais.

De outro lado, as perspectivas da economia mundial permanecem ainda extremamente incertas. Como nos anos 90, tudo depende do desempenho da economia norte-americana. Enquanto o Japão ensaia um movimento de recuperação de extensão e profundidade ainda imprevisíveis (até mesmo pela firme disposição, demonstrada inúmeras vezes nos anos 90 , dos governos japoneses em estrangular prematuramente movimentos de retomada da atividade econômica), as economias líderes da Europa ocidental, especialmente a Alemanha, debatem-se com pressões deflacionárias associadas à redução de demanda agregada que não prenunciam uma recuperação da atividade, antes pelo contrário.

Assim, uma vez mais o comportamento da economia mundial depende do que espera a economia americana ao fim de 2003 e durante 2004. Os sinais dados por aquela economia são ainda de difícil interpretação, freqüentemente inconsistentes entre si e contraditados por movimentos posteriores.

Naturalmente, além do desempenho do setor exportador, ainda é necessário saber o que ocorreria com as importações no caso de uma retomada da atividade econômica no Brasil. A contração de 
importaçōes foi elemento importante do ajuste do balanço de pagamentos brasileiro. Em parte, esta contração pode ser permanente, na medida em que alguma substituição definitiva de importações possa ter sido induzida. É discutível ainda qual a proporção da queda de importações deve-se a este movimento e qual se explica simplesmente pela queda de demanda, que seria revertida em um eventual quadro de crescimento.

Deste modo, se a política macroeconômica do presidente Lula contentou rentistas, pelo retorno oferecido pelas aplicações financeiras, tendo talvez mesmo conquistado credibilidade junto a este segmento, ela foi extremamente danosa para os setores restantes, especialmente aqueles cruciais para promover o crescimento econômico. Se nos lembrarmos que dos quatro componentes da demanda agregada, consumo privado, investimento, gastos públicos e exportações, apenas o último conta com alguma expectativa favorável, a despeito das incertezas listadas acima, é facilmente inteligível por que se chegou ao fim do sétimo mês do novo governo em clima tão desfavorável, combinando-se agitação social com extenso desencorajamento da atividade econômica. O cancelamento, ou adiamento por tempo indefinido, de planos de investimento, como tem noticiado a imprensa especializada, é particularmente preocupante porque projeta para o futuro as dificuldades do presente.

\section{O Governo Lula e Seus Críticos}

É impossível abstrair-se, ao fazer o balanço deste período do novo governo, da mudança gradativa no sentimento de que uma crise social está se gestando no país. A linguagem confiante, beirando a arrogância, de autoridades econômicas do início do governo, tem cedido lugar a pedidos de paciência, a suspensão de julgamento do desempenho do governo, e até mesmo a solicitação de sugestões de política para debate e exame no interior da nova administração. Não se pode negar, também, a disponibilização de certos canais, como o Conselho de Desenvolvimento Econômico e Social, de interação entre autoridades de governo e segmentos da sociedade, embora o eco efetivo que esta interação possa ter sobre seu processo decisório ainda esteja por ser estabelecido.

Não se pode negar, contudo, por outro lado, que por boa parte desses sete meses o convite ao debate foi pouco mais do que retórico. A abertura ao debate foi instrumento essencial da estratégia defensi- 
va do governo face aos seus críticos. A retórica defensiva definia-se pela repetição ad nauseam de dois elementos: por um lado, as críticas eram recusadas ao se perguntar "qual é a alternativa?"; por outro lado, após alguma estratégia, ou elemento de estratégia, ou a alternativa ser efetivamente oferecida, o discurso oficial era o de que a alternativa não podia ser boa, porque se fosse boa, ela já teria sido usada.

O primeiro elemento serve apenas de preparação para o segundo, este sim decisivo para fechar o argumento. Que se trata apenas de um artifício retórico, é claro pela sua própria premissa: a de que o critério de adequação de alguma proposta é a aceitação pela autoridade. $\mathrm{O}$ artificio busca estabelecer duas condiçōes essenciais: a primeira é a de coincidência de objetivos entre o crítico e o objeto da crítica; o segundo é a qualificação superior do criticado para decidir o que é ou não adequado.

Política econômica não é um processo em que meramente se escolhem instrumentos para perseguir algum fim preestabelecido. $\mathrm{Na}$ verdade, a economia coloca a todos que têm a responsabilidade de decidir a responsabilidade primeira de escolher metas entre os vários trade offs que caracterizam a vida econômica. A sociedade não é um todo indiferenciado, em que se possa definir um interesse comum, cuja busca beneficie de modo igual a todos. Ao contrário, os interesses são diferenciados, às vezes mesmo conflitantes, e a decisão de política econômica deve, antes de mais nada, arbitrar e hierarquizar estes interesses. A instrumentação é, em certo sentido, a parte mais fácil deste processo. Ao se priorizar um interesse ou outro, a definição de instrumentos é pelo menos parcialmente determinada. Quando, por exemplo, um ministro da fazenda, portanto, argumenta que se tal instrumento ou outro fosse eficaz, ele já teria sido usado, está se tentando exatamente obscurecer a possível diferença de prioridades e hierarquias de interesses que explica boa parte da diferença de instrumentação preferida. Assim, para concretizar o exemplo, quando controles de capitais são propostos, è o governo recusa a alternativa alegando que, se fossem eficazes, os controles já estariam sendo usados, o que a autoridade tenta fazer é obscurecer o fato de que controles subordinam interesses de detentores de riqueza aos interesses de outros grupos sociais. Ao preferir conquistar a simpatia dos detentores de riqueza, o governo não está simplesmente selecionando instrumentos mais eficazes de obter os mesmos resultados desejados pelos seus críticos, mas, sim, priorizando outros interesses que não aqueles priorizados pelos oponentes. 
Deste modo, a retórica defensiva do governo tenta, primeiramente, passar a idéia de que há acordo sobre metas últimas, que é o essencial, e divergências apenas de métodos. O debate mais importante, porém, não se define por instrumentos, mas por objetivos. É possível (na verdade, é muito provável) que nem mesmo toda a liderança política atualmente no poder tenha se apercebido das implicações das opções feitas. Muitos se refugiam na ilusão doce, mas, infelizmente, falsa, de que ganham tempo para promover as mudanças que planejam mais tarde. Objetivamente, contudo, a política macroeconômica implementada até aqui reflete uma priorização de interesses que certamente difere daquela imaginada, ousaríamos especular, pela maioria daqueles que votaram no candidato vitorioso em 2002.

Mas a estratégia retórica não se esgota na tentativa de pasteurização de objetivos. $\mathrm{O}$ argumento de que "fosse o instrumento proposto eficaz, ele já estaria sendo usado" estabelece como critério de eficiência desse instrumento a aceitação unilateral da proposição pela autoridade criticada. Certamente, um instrumento pode não ser utilizado porque sua eficácia é reduzida, mas também pode ocorrer simplesmente que a autoridade não seja competente para entender como ele funciona, ou esteja envolvida demais com outros interesses e prioridades, ou simplesmente não esteja á altura dos desafios que a implementação de qualquer dispositivo de política implica. Em outras palavras, o simples julgamento por uma autoridade de governo de que um instrumento não seja eficaz não serve de prova de que ele seja efetivamente ineficaz.

Como dizem os ingleses, oferecendo uma tradução pobre para a frase original, a prova do pudim é a colherad $a^{1}$. A deterioração acentuada de praticamente todos os índices macroeconômicos, com queda de consumo, de investimento, alta de desemprego, etc., é a prova do pudim. A preocupante deterioração do clima social, observada ao final destes sete meses, encontra caldo de cultura fértil na enfraquecida economia que o novo governo, em parte, herdou, mas para cuja piora contribuiu decisivamente. $\mathrm{O}$ jogo não está perdido, nem o caos é inevitável, mas uma reorientação drástica e ampla é necessária. O governo tem tentado tomar iniciativas mais construtivas, mas pontuais e limitadas, incapazes de compensar o dano causado pelas suas políticas mais importantes. As alternativas estão

${ }^{1}$ The proof of the pudding is the eating. 
propostas, são conhecidas e não vale a pena repetir aqui. Além disso, seria injusto não reconhecer que vários setores do governo parecem sinceramente interessados no diálogo, e não apenas em usálo para legitimar sua própria posição. Deste modo, o conflito entre a esperança e o medo, tão caro ao presidente, ainda pode ser resolvido em favor da primeira, mas o tempo está passando. 